\title{
Competing pathways in the reaction of the pesticide Fenitrothion [O,O-dimethyl $O$-(3-methyl-4-nitrophenyl) phosphorothioate] with some nitrogen nucleophiles in aqueous solution $\dagger$
}

\author{
Ikenna Onyido, ${ }^{\mathrm{a}^{*}}$ John E. Omakor, ${ }^{\mathrm{a}, \mathrm{b}}$ Gary W. vanLoon, ${ }^{\mathrm{b}}$ and Erwin Buncel ${ }^{\mathrm{b}^{*}}$ \\ ${ }^{a}$ Department of Chemistry and Center for Agrochemical Technology, University of Agriculture, \\ Makurdi, Nigeria ${ }^{b}$ Department of Chemistry, Queen's University, Kingston, Canada K7L 3N6 \\ *E-mail: ikennaonyido@yahoo.com; buncele@chem.queensu.ca
}

This paper is dedicated to Professor Oswald S. Tee on the occasion of his $60^{\text {th }}$ birthday and in recognition of his many contributions to chemistry in Canada

(received 21 Sep 01; accepted 17 Nov 01; published on the web 25 Nov 01)

$\dagger$ Part 5 in series on "Mechanisms of abiotic degradation and soil/water interactions of pesticides and other hydrophobic organic compounds". For previous papers in this series, see ref. 1-4.

\begin{abstract}
The reaction of the title compound, 1, with the nitrogen-based nucleophiles n-butylamine, ethanolamine, and glycyl ethyl ester, has been investigated in aqueous solution at room temperature. In all cases, attack at the phosphorus center of the substrate by the nucleophile is in competition with $\mathrm{O}-\mathrm{Ar}$ bond cleavage, the latter being an $\mathrm{S}_{\mathrm{N}} \mathrm{Ar}$ reaction. Product analyses show that the $\% \mathrm{~S}_{\mathrm{N}} \mathrm{Ar}$ product is independent of the concentration of glycyl ethyl ester but increases with n-butylamine and ethanolamine concentrations, indicating that the reactions involving $\mathrm{n}$ butylamine and ethanolamine are base catalyzed while the reaction of glycyl ethyl ester is not. The preponderance of $S_{N} A r$ products at high nucleophile concentrations argues for the ratelimiting decomposition of the Meisenheimer-type intermediates (PH) formed in the reactions of n-butylamine and ethanolamine. Formation of $\mathbf{P H}$ is rate determining in the reaction involving glycyl ethyl ester. Site preferences observed in the reaction of $\mathbf{1}$ with oxygen and nitrogen nucleophiles are discussed in terms of (i) the Hard Soft Acid Base (HSAB) theory, (ii) stabilization of the transition state for the cleavage of alkyl-O bond by hydrogen bonding, (iii) competitive advantage of nitrogen nucleophiles over their oxygen counterparts in their attack at aromatic carbon centers, and (iv) the relative ease of formation of $\sigma$-complex intermediates in $\mathrm{S}_{\mathrm{N}} \mathrm{Ar}$ reactions by amine nucleophiles compared to their oxygen counterparts.
\end{abstract}

Keywords: Fenitrothion, degradation, nucleophilic substitution, $\mathrm{S}_{\mathrm{N}} 2(\mathrm{P}), \mathrm{S}_{\mathrm{N}} 2(\mathrm{C}), \mathrm{S}_{\mathrm{N}} \mathrm{Ar}$ 


\section{Introduction}

We have embarked on a program of study of the degradation mechanisms and soil/water interactions of pesticides and some hydrophobic organic compounds under abiotic conditions as part of a strategy to evaluate the environmental chemistry of several classes of compounds that are important as agrochemicals.$^{1-4}$ The reaction of the broad spectrum insecticide fenitrothion, $\mathbf{1}$, with a variety of oxygen-based nucleophiles has engaged our recent attention. ${ }^{3,4}$ In aqueous solution, 1 reacts with a variety of oxygen nucleophiles, to include some alpha-nucleophiles and a series of structurally related phenoxides as well as the highly basic nucleophiles $\mathrm{OH}^{-}$and $\mathrm{CF}_{3} \mathrm{CH}_{2} \mathrm{O}^{-}$, exclusively at the $\mathrm{P}$ center. ${ }^{3}$ In other words, products of nucleophilic attack at the

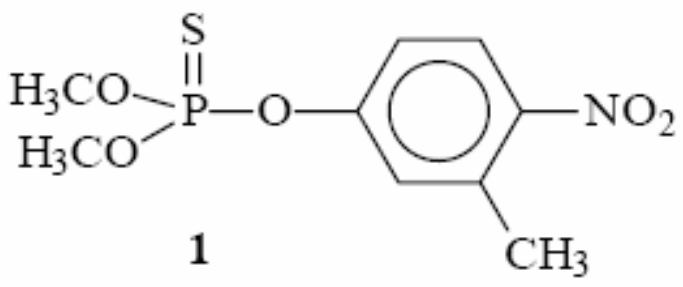

alkyl and aromatic carbon centers were not detected. Analysis of the kinetic data showed that the thiophosphoryl group transfer proceeds by a concerted mechanism in which bond formation with the incoming nucleophile is slightly ahead of leaving group departure. On the other hand, ethanolysis of 1 by alkali metal alkoxides $\left(\mathrm{M}^{+} \mathrm{EtO}^{-}, \mathrm{M}^{+}=\mathrm{Li}^{+}, \mathrm{K}^{+}\right.$, and $\left.\mathrm{Na}^{+}\right)$in anhydrous ethanol proceeds by nucleophilic attack at both $\mathrm{P}$ and aliphatic carbon centers; a minor SNAr route was also detected. ${ }^{4}$ Hence changing the nucleophile/solvent system has clearly introduced additional reaction pathways for $\mathbf{1}$. An earlier report on the hydrolysis of 1 reveals that $\mathrm{CH}_{3}-\mathrm{O}$ bond fission occurs at low $\mathrm{pH}$ while $\mathrm{P}-\mathrm{OAr}$ fission is the exclusive reaction at high $\mathrm{pH}^{5}$ To date we have found no report of the reaction of $\mathbf{1}$. with nitrogen nucleophiles, which is the subject of the present paper. Such a study would be important not only from the point of view of structurereactivity considerations, but also in contributing to the design of possible decontamination strategies for ameliorating the effects of pesticide overload in general. A recent study of phosphoryl transfer from ATP to amine nucleophiles has sought to provide a basis for understanding the analogous enzymatic reactions. ${ }^{6}$

The pathways available to $\mathbf{1}$ in its reaction with nucleophiles are shown in Scheme 1. In this paper, we report that 1 reacts with some amine nucleophiles to give mainly products of substitution at $\mathrm{P}$ and aromatic carbon centers. An attempt is made to explain site preferences in the reaction of 1 with oxygen and nitrogen nucleophiles by invoking the Hard Soft Acid Base (HSAB) theory and transition state stabilization by hydrogen bonding. The relative nucleophilicities of both nucleophile types towards aromatic carbon and the stability of $\sigma$ complex intermediates formed by them in SNAr reactions ${ }^{7}$ are additional factors which should also be considered in discussing site preferences by oxygen and nitrogen nucleophiles in their reactions with 1 and similar substrates. 


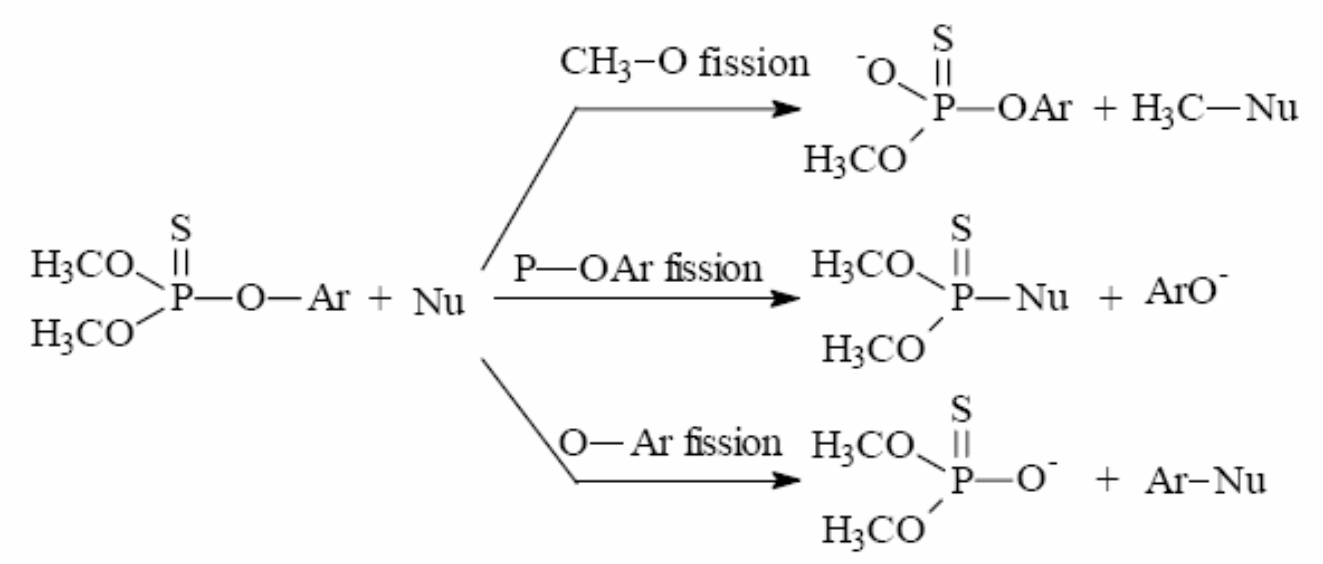

\section{Scheme 1}

\section{Results and Discussion}

\section{Reaction pathways}

3-Methyl-4-nitrophenoxide, the product of nucleophilic attack at the P center of $\mathbf{1}$, absorbs at 398 $\mathrm{nm}$. Quantitative thiophosphoryl group transfer should yield experimental absorbances at the end of the reaction which are identical to the calculated values for this nucleofuge, within experimental error. A definitive check for reactions monitored by conventional uv-visible spectrophotometry would be the measurement of absorbances at the end of the reaction at both high and low $\mathrm{pH}$. Such experiments with n-butylamine, ethanolamine, and glycyl ethyl ester revealed the presence of substituted anilines, in addition to 3-methyl-4-nitrophenoxide. The former are products of attack at the aromatic carbon center of $\mathbf{1}$.

Product analysis of the reaction of n-butylamine with 1 by GC-MS showed unambiguously the presence of $N$-butyl-3-methyl-4-nitrophenylaniline, a product of nucleophilic attack at the aromatic carbon center. Although the same chromatogram suggested the presence of minor quantities of products of $\mathrm{S}_{\mathrm{N}} 2(\mathrm{C})$ attack, these were not taken into consideration in the calculations of product distributions given below. For reactions involving ethanolamine and glycyl ethyl ester as nucleophiles, the presence of products of attack at the aromatic carbon center was inferred from spectrophotometric measurements. Values of the $\mathrm{pK}_{\mathrm{a}}$ of the amines employed in this study are listed in Table 1.

Table 1

\begin{tabular}{lc}
$\mathrm{pK}_{\mathrm{a}}$ Values of amines employed in this study & $\mathrm{a}$ \\
Amine & $\mathrm{pK}_{\mathrm{a}}\left(\mathrm{H}_{2} \mathrm{O}\right)$ \\
n-Butylamine & 10.65 \\
Ethanolamine & 9.51 \\
Glycyl ethyl ester & 7.64 \\
\hline
\end{tabular}

a Data taken from D.D Perrin, "Dissociation Constants of Organic Bases in Aqueous Solution”,IUPAC, Butterworths, London, 1965. 
The approximate \% SNAr product in each case was calculated according to equation (i),

$$
\% \mathrm{~S}_{\mathrm{N}} \mathrm{Ar} \text { product }=\left(\mathrm{A}_{\infty}-\mathrm{A}_{\mathrm{obs}}\right) / \mathrm{A}_{\infty} \times 100
$$

where $\mathrm{A}_{\infty}$ and $\mathrm{A}_{\mathrm{obs}}$ are the theoretical and observed infinity absorbances for the substituted aniline, respectively, on the assumption that the amounts of products formed by nucleophilic attack at the aliphatic carbon are negligible. The dependence of the extent of $\mathrm{S}_{\mathrm{N}} \mathrm{Ar}$ and $\mathrm{S}_{\mathrm{N}} 2(\mathrm{P})$ products formation on amine concentration is given in Table 2. It is clear that while \% $\mathrm{S}_{\mathrm{N}} \mathrm{Ar}$ product increases with amine concentration for n-butylamine and ethanolamine, the amount of $\mathrm{S}_{\mathrm{N}} \mathrm{Ar}$ product remains independent of glycyl ethyl ester concentration. This is a clear indication that the $\mathrm{S}_{\mathrm{N}} \mathrm{Ar}$ reactions of n-butylamine and ethanolamine are base catalyzed while the corresponding reaction of glycyl ethyl ester is not. Plots of $\% \mathrm{~S}_{\mathrm{N}} \mathrm{Ar}$ product $v s$. [amine], using the data of Table 2, are linear for both n-butylamine and ethanolamine (not shown).

\section{Table 2}

$\% \mathrm{~S}_{\mathrm{N}} \mathrm{Ar}$ and $\mathrm{S}_{\mathrm{N}} 2(\mathrm{P})$ products obtained in the reaction of $\mathbf{1}$ with amines in water as a function of amine concentration ${ }^{\mathrm{a}}$

\begin{tabular}{|c|c|c|c|c|c|}
\hline \multicolumn{6}{|c|}{ A. $n$-Butylamine } \\
\hline [Amine]/M & 0.05 & 0.08 & 0.11 & \multicolumn{2}{|c|}{0.14} \\
\hline$\% \mathrm{~S}_{\mathrm{N}} \mathrm{Ar}$ product & 50.4 & 55.1 & 59.3 & \multicolumn{2}{|c|}{63.1} \\
\hline$\% \mathrm{SN} 2(\mathrm{P})$ product & 49.6 & 44.9 & 40.7 & \multicolumn{2}{|c|}{36.9} \\
\hline \multicolumn{6}{|c|}{ B. Ethanolamine } \\
\hline$[$ Amine $] / \mathrm{M}$ & 0.10 & 0.20 & 0.40 & 0.60 & 0.80 \\
\hline$\% \mathrm{~S}_{\mathrm{N}} \mathrm{Ar}$ product & 73.6 & 77.2 & 78.8 & 82.3 & 85.1 \\
\hline$\% \mathrm{~S}_{\mathrm{N}} 2(\mathrm{P})$ product & 26.4 & 22.8 & 21.2 & 17.7 & 14.9 \\
\hline \multicolumn{6}{|c|}{ C. Glycyl ethyl ester } \\
\hline [Amine $] / \mathrm{M}$ & 0.20 & 0.40 & 0.60 & 0.80 & 0.96 \\
\hline$\% \mathrm{~S}_{\mathrm{N}} \mathrm{Ar}$ product & 62.4 & 64.0 & 59.2 & 59.2 & 60.0 \\
\hline$\% \mathrm{~S}_{\mathrm{N}} 2(\mathrm{P})$ product & 37.6 & 36.0 & 40.8 & 40.8 & 40.0 \\
\hline
\end{tabular}

\section{Base catalysis and the mechanism of the $S_{\mathrm{N}} A r$ reaction}

The gross mechanism for $S_{N} A r$ reactions is given in Scheme 2, in which either the formation of the Meisenheimer-type intermediate, PH, or its decomposition to products could be rate determining. According to this mechanism, the observed second-order rate constant, $\mathrm{k}_{\mathrm{A}}$, is related to the microscopic rate constants for the constituent steps through equation (ii).

$$
\mathrm{k}_{\mathrm{A}}=\mathrm{k}_{1}\left(\mathrm{k}_{2}+\mathrm{k}_{3}[\mathrm{~B}]\right) /\left(\mathrm{k}_{-1}+\mathrm{k}_{2}+\mathrm{k}_{3}[\mathrm{~B}]\right)
$$

The three nucleophiles investigated in this study are all primary amines; there is therefore 
structural similarity, in a sense, among them. The results presented above show that while the $\mathrm{S}_{\mathrm{N}} \mathrm{Ar}$ reactions of $\mathrm{n}$-butylamine and ethanolamine proceed by way of rate-determining decomposition of PH (Scheme 2), its formation is rate-limiting for glycyl ethyl ester. With reference to equation (ii), what these results indicate is that for the reactions involving $\mathrm{n}$ butylamine and ethanolamine, the kinetic condition $\mathrm{k}_{-1}>>\mathrm{k}_{2}+\mathrm{k}_{3}[\mathrm{~B}]$ holds, while for the reaction of glycyl ethyl ester the kinetic condition $\mathrm{k}_{-1}<\mathrm{k}_{2}+\mathrm{k}_{3}$ [B] obtains. The factors determining the incidence of base catalysis or otherwise in SNAr reactions are now well known and have been discussed extensively. ${ }^{7-16}$

Kirby and Jencks, ${ }^{17}$ have reported that primary and secondary amines react with pnitrophenyl phosphate dianion in aqueous solutions at both $\mathrm{P}$ and aromatic carbon sites; at the latter reaction site, the primary amines investigated did not show any susceptibility to base catalysis while secondary amines participated in reactions which showed varying degrees of response to base catalysis. Such dichotomy in the response of primary and secondary amines to base catalysis in SNAr reactions involving moderately to strongly activated substrates is well documented and the causative factors have also been discussed. ${ }^{18,25}$ Bernasconi's review ${ }^{26}$ provides several examples of $S_{N} A r$ reactions of less activated substrates which are catalyzed by strongly and moderately basic amines, as found in the present study.

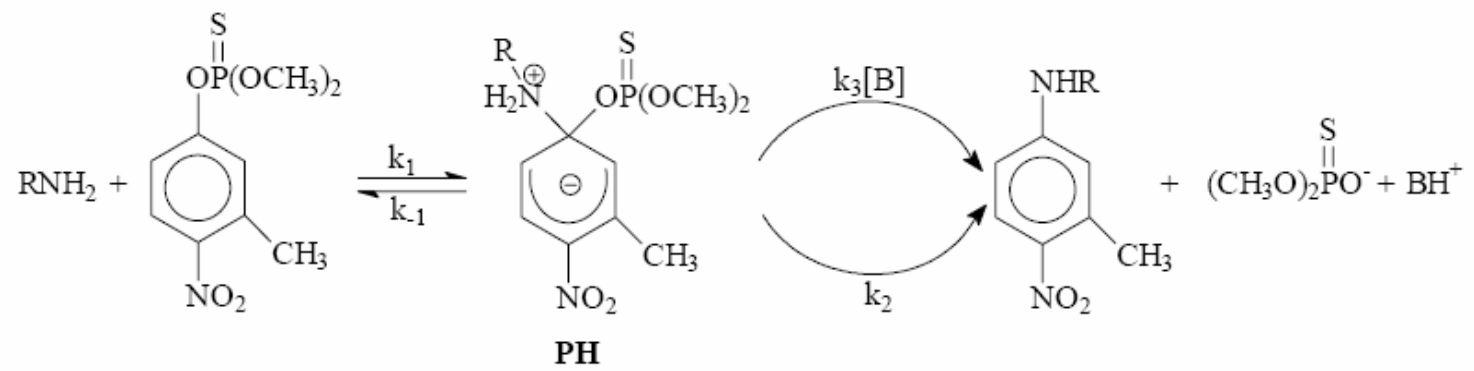

\section{Scheme 2}

\section{Site preferences in the reaction of 1 with oxygen and nitrogen nucleophiles}

The reactions of organophosphorus compounds with various types of nucleophiles have been studied by numerous workers in the field of organophosphorus chemistry and a large body of data is available. ${ }^{27-36}$ Khan and Kirby ${ }^{37}$ have published on the multiple structure-reactivity correlations for reactions of phosphate triesters with a variety of nucleophiles. What is clear from the literature is that reactivities are sensitive to substrate structure, nucleophile type and basicity, nature of the leaving group, solvent type and solvation factors, etc. ${ }^{27-31,39,40}$ Our intention in this section is to keep the substrate constant while examining how change of nucleophile type, from oxygen to nitrogen nucleophiles, influences reaction site preferences especially in alkaline media. In this way, it is hoped that an appreciation of some of the factors that determine site preferences will emerge. It is noted that existing literature comparisons do not incorporate significant information on $\mathrm{P}=\mathrm{S}$ substrates such as $\mathbf{1}$, the subject of the present investigation.

To summarize, the following are the results so far obtained in the reactions of 1 with oxygen 
and nitrogen nucleophiles in water and ethanol as solvents. At $\mathrm{pH} \leq 7.5$, hydrolysis of 1 in aqueous solutions proceeds by way of alkyl-O bond fission; at higher $\mathrm{pH}(>9)$, reaction occurs exclusively by displacement of ArO'through attack at the $\mathrm{P}$ center. ${ }^{5,6}$ In ethanol, the predominant products are those of alkyl-O (ca. $43 \%$ ) and P-OAr (ca.50\%) bond fission; a minor $\mathrm{S}_{\mathrm{N}} \mathrm{Ar}$ pathway, accounting for ca.7\% of the reaction products, was observed. ${ }^{4}$ With a series of structurally related phenoxides as nucleophiles, reaction in water occurs exclusively at the $\mathrm{P}$ center. ${ }^{3}$ Changing the nucleophile to the primary amines used in the present study sets up a competitive process in which attack at the aromatic carbon center is favored to varying extents over the corresponding reaction at $\mathrm{P}$.

The behavior of these nucleophiles in alkaline media in their reaction with $\mathbf{1}$ is amenable to an explanation that is based on the HSAB theory, ${ }^{41}$ in which case the "hard" oxygen bases react mainly with the "hard" $\mathrm{P}$ center. The fact that "hard" amine nucleophiles, whose basicities are comparable to those of the oxyanions studied previously, show considerable affinity for the aromatic carbon center as well could be attributed to two factors. Firstly, Terrier ${ }^{42}$ has shown that amines are intrinsically more reactive than alkoxides of similar basicities towards aromatic carbon centers. This may not be unconnected, in part, with the need to desolvate alkoxide reagents in an activated process which precedes the actual step involving nucleophilic attack. Jencks' results ${ }^{43,44}$ demonstrate that amines and thiolates generally tend to be more nucleophilic than oxyanions, essentially as a consequence of the decreased demand for solvation of these nucleophiles as well as the high carbon basicity of thiolates, in comparison to oxyanions. Secondly, protic amine nucleophiles have been demonstrated to form $\sigma$-complexes with some trinitro-activated aromatic substrates with greater ease when compared with O-based nucleophiles at ambient temperatures. ${ }^{45-48}$ Primary and secondary amine nucleophiles form $\sigma$ complexes quite readily, in part because the deprotonation of the first-formed intermediate (see Scheme 2) provides the thermodynamic driving force for the forward reaction, and this effect is lacking when O-based nucleophiles are involved. This factor disfavoring the reaction of O-based nucleophiles should assume greater prominence when the aromatic moiety is much less activated, as in 1. On this score, the observation of SNAr products with amines but not with oxygen nucleophiles can be accounted for.

The formation of significant amounts of $S_{N} 2(C)$ products in the ethanolysis of $\mathbf{1}$ by alkali metal ethoxide in ethanol recently reported by Buncel and co-workers, ${ }^{4}$ can be understood if the bulk solvent stabilizes the transition state for alkyl-O bond cleavage through hydrogen bonding to the departing ${ }^{-} \mathrm{OP}(\mathrm{S})\left(\mathrm{OCH}_{3}\right) \mathrm{OAr}$ anion. These authors showed that free ethoxide is more reactive than either ion paired or dimerized alkali metal ethoxide. Attack by ethoxide at the $P$ center is catalyzed by alkali metal ethoxides. In addition to the products of attack at the $\mathrm{P}$ center, which are explicable by the HSAB theory, minor products of ethoxide ion attack at the aromatic carbon center were also observed. The latter products conceivably result from the nucleophilic activity of the significantly more basic $\mathrm{EtO}^{-}$, which promotes attack at the aromatic center in a reaction that is considerably less favored than the processes at the $\mathrm{P}$ and alkyl carbon centers. Kirby and Younas ${ }^{49}$ have shown that changing oxyanion nucleophiles to more basic ones in the 
reaction of methyl 2,4-dinitrophenyl phosphate enhances the prospects of SNAr product formation, in addition to attack at the $\mathrm{P}$ center.

\section{Experimental Section}

General Procedures. Materials. Reagents were commercial products which were either used as received or purified according to literature procedures. Stock solutions of the substrate were prepared under nitrogen and stored in volumetric flasks which were sealed with rubber septa, protected from light by wrapping with aluminum foil and stored in a refrigerator. $\mathrm{pH}$ was measured with an Accumet $825 \mathrm{pH}$ meter with a glass electrode calibrated with standard buffer solutions. NMR spectra of the substrate were obtained on a Bruker 400 spectrometer operating at $400 \mathrm{MHz}$. Product analysis by GC-MS was performed using a Fisons 8000 Gas Chromatography instrument equipped with a MD800 Mass Spectrometer. The GC was equipped with a DB-5 capillary column, and used helium as the carrier gas. The qualitative experiments for the determination of reaction products for processes involving the three amines investigated were performed on a Perkin-Elmer Lambda 5 uv-visible spectrophotometer. Water was distilled, deionized, degassed, and filtered through $0.22 \mu \mathrm{m}$ filter.

O,O-Dimethyl-O-(3-methyl-4-nitrophenyl)phosphorothioate, 1, was a gift from Sumitomo Chemical Co. and was purified by column chromatography; ${ }^{50}$ its purity was checked by ${ }^{1} \mathrm{H}$ and ${ }^{31} \mathrm{P}$ NMR as well as by GC-MS.

\section{Determination of reaction products}

Reaction was initiated by injecting the required amount of a stock solution $\left(9.54 \times 10^{-3} \mathrm{M}\right)$ of $\mathbf{1}$ into a capped glass vial containing the appropriate concentration of the relevant amine at room temperature. In all cases, the amine concentration was in large excess of the substrate. The $\mathrm{pH}$ of the reaction mixture was measured. Aliquots of the reaction mixture were then withdrawn, its $\mathrm{pH}$ was adjusted to $<5$ with dilute $\mathrm{HCl}$ and the absorbance measured at $400 \mathrm{~nm}$. At this $\mathrm{pH}$, the absorbances recorded were those due to substituted anilines, i.e. the $\mathrm{S}_{N} A r$ products, since the phenolate products resulting from displacement at the $\mathrm{P}$ center would exist in their protonated forms, i.e. the phenols, which would not absorb at $\mathrm{pH}<5$. The absorbance of the reaction mixture was monitored until no further changes were observed. In all cases, experimental absorbances at "infinite" time were lower than calculated ones, indicating the existence of competing reaction(s). The observed and theoretical infinity absorbances were used to calculate $\% \mathrm{~S}_{\mathrm{N}} \mathrm{Ar}$ reaction products according to equation (i). The $\% \mathrm{~S}_{\mathrm{N}} 2(\mathrm{P})$ products recorded in Table 2 were obtained by difference, on the assumption that the amounts of $\mathrm{S}_{\mathrm{N}} 2(\mathrm{C})$ products formed by nucleophilic attack at the aliphatic carbon are negligible. 


\section{Acknowledgments}

We thank the Natural Sciences and Engineering Research Council of Canada (G.vL. and E.B.) and the Canadian International Development Agency (I.O. and J.E.O.) for supporting this work. Helpful comments by Vimal Balakrishnan are also gratefully acknowledged. One of us (I.O.) thanks Professor Per Ahlberg for his hospitality during a visit in which part of this manuscript was prepared.

\section{References}

1. Annandale, M. T.; vanLoon, G. W.; Buncel, E. Can. J. Chem. 1998, 76, 873.

2. Sha'ato, R.; Buncel, E.; Gamble, D. G.; vanLoon, G. W. Can. J. Soil Sci. 2000, 80, 301.

3. Omakor, J. E. ; Onyido, I.; vanLoon, G. W.; Buncel, E. J. Chem. Soc., Perkin Trans. 2 2001, 324.

4. Balakrishnan, V. M. ; Dust, J. M.; vanLoon, G. W.; Buncel, E. Can. J. 157.

5. Greenhalgh, R.; Dhawan, K. L.; Weinberger, P. J. Agric. Food Chem., 1980, 28, 102.

6. Admiraal S. J.; Herschlag, D. J. Am. Chem. Soc. 1999, 121, 5837.

7. Bunnett, J. F.; Garbisch, Jr., E. W.; Pruit, K. M. J. Am. Chem. Soc. 1957, 79, 385.

8. Onyido, I.; Ubochi, C. I. J. Chem. Soc., Perkin Trans. 2 1987, 563.

9. Onyido, I.; Ubochi, C. I. Heterocycles 1987, 26, 313.

10. Buncel, E.; Crampton, M. R.; Strauss, M.J; Terrier, F. Electron Deficient Aromatic- and Heteroaromatic - Base Interactions, Elsevier: Amsterdam, 1984.

11. Buncel, E.; Dust, J. M.; Terrier, F. Chem. Rev., 1995, 95, 2261.

12. Orvik, J. A.; Bunnett, J. F. J. Am. Chem. Soc., 1970, 92, 2417.

13. Hasegawa, Y. J. Chem. Soc. Perkin Trans. 2, 1985, 87.

14. Bernasconi, C. F.; Terrier, F. J. Am. Chem. Soc. 1975, 97, 7458.

15. Bernasconi, C. F. J. Phys. Chem. 1971, 75, 3636.

16. Bernasconi, C. F. Acc. Chem. Res. 1978, 11, 147.

17. A.J. Kirby and W.P Jencks, J. Am. Chem. Soc. 1965, 87, 3217.

18. J.F. Bunnett and C.F. Bernasconi, J. Am. Chem. Soc. 1965, 87, 5209.

19. Pietra, F. Tetrahedron Lett. 1975, 2405.

20. Emokpae, T. A.; Uwakwe, P.; Hirst, J. J. Chem. Soc., Perkin Trans. 2 1993, 125.

21. Crampton, M. R.; Lord, S.D. J. Chem. Soc. Perkin Trans. 2 1997, 369.

22. Ayediran, D.; Bamkole, T. O.; Hirst, J. J. Chem. Soc., Perkin Trans 2 1976, 1396.

23. Ayediran, D.; Bamkole, T. O.; Hirst, J.; Onyido, I. J. Chem. Soc. Perkin Trans 2 1977, 1580.

24. Hirst, J.; Hussain, G.; Onyido, I. J. Chem. Soc. Perkin Trans. 2 1986, 397.

25. Akinyele, E. T.; Onyido, I.; Hirst, J. J. Phys. Org. Chem. 1990, 3, 41.

26. Bernasconi, C. F. MTP Int. Rev. Sci. Org. Chem. Ser. One 1973, 3, 33.

27. Thatcher, G. R. J.; Kluger, R. Adv. Phys. Org. Chem. 1989, 25, 99. 
28. Jencks, W. P. Chem. Rev. 1985, 85, 511.

29. Herschlag, D.; Jencks, W. P. J. Am. Chem. Soc. 1990, 112, 1951.

30. Herschlag, D.; Jencks, W.P. J. Am. Chem. Soc. 1989, 111, 7587.

31. Admiraal, S .J.; Herschlag, D. J. Am. Chem. Soc. 2000, 122, 2145.

32. Williams, A. Chem. Soc. Rev. 1994, 93.

33. Williams, A. Adv. Phys. Org. Chem. 1992, 27, 1.

34. Williams, A. Acc. Chem. Res. 1989, 22, 387.

35. Pregel, M. J.; Dunn, E. J.; Nagelkerke, R.; Thatcher, G. R. J; Buncel, E. Chem. Soc. Rev. 1995, 24, 449.

36. Hudson, R. F. Structure and Mechanism in Organophosphorus Chemistry, Academic Press: New York, 1985.

37. Khan, S. A.; Kirby, A. J. J. Chem. Soc. (B) 1970, 1172.

38. Kirby, A. J.; Warren, S. G. The Organic Chemistry of Phosphorus, Elsevier: London, 1966.

39. Bunton, C. A.; Robinson, L. J. Org. Chem. 1969, 34, 773.

40. Kirby, A. J.; Varvoglis, A. G. J. Am. Chem. Soc. 1967, 89, 415.

41. Pearson, R.G. Surv. Prog. Chem., 1969, 5, 1; Inorg. Chem. 1988, 27, 734.

42. Terrier, F. Nucleophilic Aromatic Displacement, VCH: New York, 1991.

43. Jencks, W. P.; Gilchrist, M. J. Am. Chem. Soc. 1968, 90, 2622.

44. Jencks, W. P.; Carriuolo, J. J. Am. Chem. Soc. 1960, 82, 1778.

45. Buncel, E.; Jonczyk, A.; Webb, J. G. K. Can. J. Chem. 1975, 53, 3761.

46. Buncel, E.; Webb, J. G. K. J. Am. Chem. Soc. 1973, 95, 8470.

47. Buncel, E.; Dust, J. M.; Manderville, R. A.; Park, K.-T; Onyido, I. Bull. Soc. Chim. France 1988, 371.

48. Buncel, E.; Dust, J. M.; Jonczyk, A.; Manderville, R. A.; Onyido, I. J. Am. Chem. Soc. 1992, 114, 5610.

49. Kirby, A. J.; Younas, M. J. Chem. Soc. 1970, 1165

50. Nishizawa, Y.; $\quad$ Nakagawa, M.; Suzuki, Y.; Sakamoto, H.; Mizutani, T. Agric. Biol. Chem. 1961, 25, 597. 